Research Paper

\title{
Risk-Factor Analysis of Poor Graft Function after Allogeneic Hematopoietic Stem Cell Transplantation
}

\author{
Yang $\mathrm{Xiao}^{* \otimes}$,Jiayin Song ${ }^{*}$, Zujun Jiang, Yonghua Li, Yang Gao, Wenning Xu, Ziyuan Lu, Yaochun Wang, \\ Haowen Xiao ${ }^{\bowtie}$ \\ Department of Hematology, Guangzhou General Hospital of Guangzhou Military Command, Guangzhou 510010, China \\ *These author contributed equally to this study. \\ $\square$ Corresponding author: Yang Xiao, Department of Hematology, Guangzhou General Hospital of Guangzhou Military Command, No. 111 Liuhua Road, \\ Guangzhou 510010, China. Tel: +86-20-36653562 Fax: +86-20-36653562 Email: jdxiao111@163.com, or Haowen Xiao, Department of Hematology, Guangzhou \\ General Hospital of Guangzhou Military Command, No. 111 Liuhua Road, Guangzhou 510010, China. Tel: +86-20-36654557 Fax: +86-20-36654558 Email: \\ haowenxiao1974@hotmail.com.
}

() Ivyspring International Publisher. This is an open-access article distributed under the terms of the Creative Commons License (http://creativecommons.org/ licenses/by-nc-nd/3.0/). Reproduction is permitted for personal, noncommercial use, provided that the article is in whole, unmodified, and properly cited.

Received: 2013.03.26; Accepted: 2014.01.20; Published: 2014.04.30

\begin{abstract}
The objective of this study was to investigate the main risk factors for poor graft function (PGF) after allogeneic hematopoietic stem cell transplantation (allo-HSCT), to allow the improvement of transplantation outcomes through preventive measures. Clinical data for 124 patients who received allo-HSCT were analyzed retrospectively. There were 83 males $(66.9 \%)$ and $4 \mathrm{I}$ females (33.1\%) with a median age of 28 years (4-60 years). The median follow-up time was 7 months (I-116 months). Factors analyzed included age, gender, disease diagnosis, source of hematopoietic stem cells, donor type, human leukocyte antigen (HLA) matching, conditioning regimen, numbers of infused mononuclear cells and $\mathrm{CD} 34^{+}$cells, donor-recipient sex and blood-type matching, prophylactic treatment of graft-versus-host disease (GVHD), grades of GVHD, Epstein-Barr virus or cytomegalovirus (CMV) infection, post-transplantation lymphoproliferative disorders and hepatic veno-occlusive disease. Data were analyzed by univariate and multivariate conditional logistic regression analyses. Among the 124 patients who underwent allo-HSCT, 15 developed PGF (12.1\%). Univariate logistic regression analysis identified age, donor-recipient blood type and CMV infection (in 30 days) as potential risk factors for PGF. Multivariate analysis of factors with $\mathrm{P}<0 . \mathrm{I}$ in univariate analysis showed that age, donor-recipient blood type and CMV infection (in 30 days) were significant risk factors for PGF. Patients were divided into subgroups based on age $<20,20-30,30-40$, and $>40$ years. The risk of PGF increased 2.747-fold (odds ratio $(O R)=2.625,95 \%$ confidence interval: I.4I I-5.347) for each increment in age level. Patients with mismatched blood type $(O R=4.05 \mathrm{I})$ or $C M V$ infection $(O R=9.146)$ had an increased risk of PGF. We conclude that age, donor-recipient blood-type matching and CMV infection are major risk factors for PGF after allo-HSCT.
\end{abstract}

Key words: Allogeneic hematopoietic stem cell transplantation, Poor graft function, Hematopoietic reconstitution, Risk factor, Graft-versus-host disease.

\section{Introduction}

Allogeneic hematopoietic stem cell transplantation (allo-HSCT) involves the transplantation of donor hematopoietic stem cells into recipients who have received high-dose radiotherapy and chemotherapy or immunosuppressive agents to eliminate tumor cells or abnormal clonal cells. This medical procedure reconstitutes the recipient's normal hematopoietic and immune systems, and has been used widely to treat various non-malignant and malignant hematopoietic diseases, solid tumors, and autoimmune and 
congenital diseases

Successful HSCT is associated with good survival of donor stem cells in the recipient's body and subsequent reconstitution or recovery of the patient's hematopoietic function. However, successful HSCT not only depends on adequate and high-quality hematopoietic stem cells, but also requires a properly-functioning microenvironment. Although high-dose radiochemotherapy pre-transplantation can kill the tumor tissues and hematopoietic stromal cells, it may also irreversibly damage the bone marrow stromal cells and dramatically bone marrow fibroblast colony-forming units. Importantly, it could further destroy the bone marrow microenvironment, resulting in poor graft function (PGF) after transplantation [1].

Despite recent outstanding progresses in preventing transplantation complications, the occurrence and fatality rates of graft-versus-host disease (GVHD) and PGF after allo-HSCT remain high, and may be limiting factors in the clinical application of allo-HSCT $[2,3]$. The present study retrospectively analyzed the clinical data for 124 patients who underwent allo-HSCT, in order to explore the major risk factors for PGF. It is hoped that identification of the risk factors will enable preventive measures to be taken, thus improving transplantation outcomes.

\section{Materials and Methods}

\section{Objectives}

Clinical data for 124 patients with malignant hematopoietic diseases who received allo-HSCT in Guangzhou General Hospital of Guangzhou Military Command between June 2009 and September 2012 were analyzed retrospectively. There were 83 males $(66.9 \%)$ and 41 females $(33.1 \%)$. The median age was 28 years (4-60 years) oldAccording to World Health Organisation criteria, National Comprehensive Cancer Network guidelines and Williams Hematology on hematopoietic stem cell transplantation, 17 patients were diagnosed with acute lymphocytic leukemia, 41 with acute myelocytic leukemia, 28 with chronic myelocytic leukemia, three with megakaryocytic acute leukemia, 10 with myelodysplasia syndrome, seven with non-Hodgkin lymphoma, one with paroxysmal nocturnal hemoglobinuria aplastic anemia syndrome, 11 with severe aplastic anemia, five with thalassemia, and one with primary immunodeficiency diseases. Written informed consent was obtained from all the patients and/or their relatives prior to the study. The study protocol was approved by the ethics committee of Guangzhou General Hospital of Guangzhou Military Command.

\section{Poor graft function criteria}

PGF was diagnosed in patients with two or three cytopenic lines (hemoglobin $<100 \mathrm{~g} / \mathrm{L}$, neutrophil count $<1.0 \times 10^{9} / \mathrm{L}$, platelet count $<30 \times 10^{9} / \mathrm{L}$ ) at day +30 post-transplant, with transfusion requirements, associated with hypoplastic-aplastic bone marrow, in the presence of complete donor chimerism and in the absence of severe GVHD and relapse.

\section{Transplantation}

\section{Transplant data by donor type}

A total of 79 patients underwent related-donor HSCT and 45 underwent unrelated-donor HSCT. Human leukocyte antigen types (HLA) were assessed by sequence-based typing. High-resolution detection assays were performed for HLA-A, HLA-B, HLA-C, HLA-DRB1 and HLA-DQB1 loci. Seventy-five patients were fully HLA-matched, six had one HLA mismatch, 18 had two HLA mismatches and 10 had more than three HLA mismatches.

\section{Hematopoietic stem cell mobilization, collection and} reinfusion

A total of $5-10 \mu \mathrm{g} / \mathrm{kg}$ granulocyte colony-stimulating factor (G-CSF) was administered subcutaneously to the donors on a daily basis for 5 days.. Peripheral blood stem cells were collected from donors on the fourth and fifth days using a blood cell separator (Fresenius kabi LLC). The peripheral blood leukocyte count was $20-40 \times 10^{9} / \mathrm{L}$.

For patients who underwent bone marrow transplantation (BMT), bone marrow was harvested from the posterior ilium of donors under local anesthesia on the fourth day, at $5 \mathrm{ml} / \mathrm{kg}$ of patient, according to standard procedures. The collection criteria included: mononuclear cells $\geq 5 \times 10^{8} / \mathrm{kg}$ and $\mathrm{CD} 4^{+}$ cells $\geq 2 \times 10^{6} / \mathrm{kg}$. The ratio of bone marrow cells to peripheral blood cells was approximately 1:2 in the case of BMT+PBSCT. Among the transplantation cases, seven received BMT, 89 received PBSCT and 28 underwent PBSCT+BMT. Red blood cells or blood plasma in the bone marrow were eliminated in patients with mismatched blood types. Bone marrow suspension was transfused immediately into patients without in vitro T-lymphocyte manipulation.

\section{Conditioning regimen}

The conditioning regimens for patients scheduled for BMT or PBSCT consisted of busulfan $(\mathrm{BU})+$ cyclophosphamide $(\mathrm{CY})$ in 17; modified BU+CY $(\mathrm{BU}+\mathrm{CY}+\mathrm{Ara}-\mathrm{c})$ in 46; BU+fludarabine (Flu) in seven; $\mathrm{CY}+$ antithymocyte globulin (ATG) in nine; $\mathrm{Flu}+\mathrm{Ara}-\mathrm{C}+\mathrm{BU}+\mathrm{CY}$ in 13; Flu+Ara-C+total body irradiation $(\mathrm{TBI})+\mathrm{CY}$ in two; Flu+ATG+BU+CY in six; 
$\mathrm{TBI}+\mathrm{CY}$ in 10; tomotherapy+CY in three, and other conditioning regimens in 11.

\section{Prophylaxis and treatment of GVHD}

The GVHD prevention regimen was performed as follows. HLA-identical donors were treated with cyclosporine (CsA) and short-term methotrexate (MTX). On day 1 after transplantation, $15 \mathrm{mg} / \mathrm{m}^{2}$ MTX was injected intravenously (iv.), followed by 10 $\mathrm{mg} / \mathrm{m}^{2}$ MTX iv. on days +3 , +6, and +11 . HLA-mismatched donors were treated with $\mathrm{CsA}+\mathrm{MTX}+\mathrm{ATG} \pm$ mycophenolate mofetil. If no acute GVHD was diagnosed, CsA was withdrawn for 3 (HLA-identical sibling donor transplantation) or 6 months (other donor transplantation). Acute and chronic GVHD were diagnosed according to clinical symptoms and/or biopsy evidence from the skin, liver, gastrointestinal tract and/or buccal mucosa.

\section{Supportive care and infection prophylaxis}

All patients were in a laminar-flow ward. Supportive care was provided after HSCT to sustain normal organ functions (liver, heart and gastrointestinal mucosa).

Oral sulfamethoxazole $(0.96 \mathrm{~g}$ bid $)$, piperacillin and sulbactam (2.5 g iv. bid), and oral norfloxacin (400mg bid) were given to all patients for prophylaxis against gastrointestinal bacterial infection and Pneumocystis carinii infection.

Fluconazole $(0.3 \mathrm{~g} /$ day from days -5 to +60$)$ was used in patients with no history of invasive fungal infection, while patients with a history of invasive fungal infection received iv. itraconazole $(0.4 \mathrm{~g} /$ day $)$, or voriconazole $(0.4 \mathrm{~g} /$ day $)$, or AmBisome (2 $\mathrm{mg} / \mathrm{kg} /$ day). Oral itraconazole and voriconazole were started when the peripheral white blood cell (WBC) count exceeded $2.0 \times 10^{9} / \mathrm{L}$ and was discontinued after 90 days post-transplantation.

Mesna was administered routinely to prevent hemorrhagic cystitis. Phenytoin sodium was used to prevent possible Bu-induced epilepsy. Low-molecular-weight heparin (5000 U) was administered subcutaneously once daily. Prostaglandin E1 $(0.5 \mu \mathrm{g} / \mathrm{kg}$ per day iv.) was infused from days $8-30$ after HSCT to prevent hepatic veno-occlusive disease (VOD). G-CSF ( $5 \mu \mathrm{g} / \mathrm{kg}$ per day) was administrated on the third day post-transplantation until the WBC count exceeded $4.0 \times 10^{9} / \mathrm{L}$ or the continuous neutrophil count exceeded $0.5 \times 10^{9} / \mathrm{L}$. Patients with hemoglobin $<70 \mathrm{~g} / \mathrm{L}$ were transfused with red blood cell concentrates. Patients with platelet counts $<20 \times 10^{9} / \mathrm{L}$ were transfused with fresh platelet supernatant. Gamma globulin (5-10 g/day iv. infusion) was also used as an assisted treatment.

\section{CMV prophylaxis}

All patients received prophylactic ganciclovir (5 $\mathrm{mg} / \mathrm{kg}$ iv. bid.) from day -14 until day -1 , and prophylactic acyclovir $(10 \mathrm{mg} / \mathrm{kg}$ iv. bid) from day -1 until the WBC count exceeded $4.0 \times 10^{9} / \mathrm{L}$ or the continuous neutrophil count exceeded $0.5 \times 10^{9} / \mathrm{L}$ post-transplantation.

\section{Definitions and CMV surveillance and therapy}

CMV infection was defined by a positive pp65 antigenemia assay or CMV DNA detection in two consecutive blood samples. CMV disease was defined as otherwise unexplained organ dysfunction with CMV infection.

CMV infection was monitored by pp65 antigenemia at least once a week, starting on day -14 until day +180 post-transplant. Results are expressed as the number of CMV pp65-positive cells per $2 \times 10^{5}$ peripheral blood lymphocytes. If WBC counts were not sufficiently high $\left(<200 / \mathrm{mm}^{3}\right)$ for the pp65 assay during the pre-engraftment phase, CMV PCR was used. Patients received therapy if the CMV-DNA copy number was increased $(\geq 500$ copy $/ \mathrm{ml})$ or related clinical symptoms were observed.

All patients with evidence of CMV infection were treated with an induction dose of ganciclovir 5 $\mathrm{mg} / \mathrm{kg}$ iv. bid for 14 days, irrespective of the number of CMV-positive cells, started on the first day of PCR-positivity until negative CMV antigenemia. If the CMV-PCR assay remained positive after 2 weeks, ganciclovir was continued for an additional 2 weeks. Foscarnet $60 \mathrm{mg} / \mathrm{kg}$ iv. q8h was administered to patients who remained PCR-positive after 4 weeks of treatment.

\section{Statistical analysis}

All the clinical data were analyzed retrospectively using SPSS package software (SPSS, Chicago, IL, USA). Univariate analysis consisted of calculating crude PGF incidence rates by levels of risk factors, and comparing crude incidence rates among different levels of risk factors using Pearson's $\chi^{2}$ test or Fisher's exact test, if the theoretical frequency of any cell was $<5$. Risk factors with borderline significance $(\mathrm{P}<0.1)$ in univariate analysis were chosen for further evaluation by multivariate logistic regression. Significant risk factors were added to the final model using a stepwise forward method with significance margins for entry of 0.10 and removal of 0.15

\section{Results}

\section{Univariate analysis of risk factors for PGF (Table I)}

The median follow-up time was 7 months (1-116 
months) by September 2012. Among the 124 patients who received allo-HSCT, 15 experienced PGF (12.1\%), while the remaining 109 did not $(87.9 \%)$. Univariate analysis using Pearson's $\chi^{2}$ test or Fisher's exact test indicated that gender, disease type $(\mathrm{P}=0.964)$, donor age, donor-recipient relatedness, number of HLA mismatches $(\mathrm{P}=0.488)$, graft source, conditioning regimen, GVHD prevention regimen, Epstein Barr virus infection, time from diagnosis to transplantation, pre- and post-transplantation infections, previous hepatitis B, and infusion of mononuclear CD34 cells were not risk factors for PGF. In addition, HLA typing was not associated with PGF $(\mathrm{P}=0.388)$. However, patient age, donor-recipient blood-type matching and CMV infection (in 30 days) were potential risk factors for PGF.

Table I. The association between the risk factors and PGF incidence.

\begin{tabular}{|c|c|c|c|c|c|}
\hline \multirow[t]{2}{*}{ Variables } & \multirow[t]{2}{*}{ Group } & \multicolumn{2}{|c|}{ Number of patients } & \multirow[t]{2}{*}{$x^{2 *}$} & \multirow[t]{2}{*}{ P vale } \\
\hline & & No-PGF, N (\%) & PGF, N (\%) & & \\
\hline & $<20$ & $22(20.2)$ & $2(13.3)$ & 12.914 & $0.002^{\#}$ \\
\hline \multirow[t]{3}{*}{ Age of the patient } & $20 \sim 30$ & $46(42.2)$ & $1(6.7)$ & & \\
\hline & $30 \sim 40$ & $24(22.0)$ & $4(26.7)$ & & \\
\hline & $>40$ & 17(15.6) & $8(53.3)$ & & \\
\hline \multirow[t]{2}{*}{ Sex } & Male & $74(67.9)$ & $9(60.0)$ & - & 0.567 \\
\hline & Female & $35(32.1)$ & $6(40.0)$ & & \\
\hline \multirow[t]{8}{*}{ Disease, } & ALL & $15(14.0)$ & $2(13.3)$ & 5.972 & 0.461 \\
\hline & AML & $37(34.6)$ & $4(26.7)$ & & \\
\hline & CML & $25(23.4)$ & $3(20.0)$ & & \\
\hline & MAL & $2(1.9)$ & $1(6.7)$ & & \\
\hline & MDS & $7(6.5)$ & $3(20.0)$ & & \\
\hline & NHL & $7(6.5)$ & $0(0.0)$ & & \\
\hline & SAA & $9(8.4)$ & $2(13.3)$ & & \\
\hline & THALASSEMIA & $5(4.7)$ & $0(0.0)$ & & \\
\hline \multirow{4}{*}{ Age of the donor } & $<20$ & $13(21.0)$ & $0(0.0)$ & 5.051 & 0.137 \\
\hline & $20 \sim 30$ & $26(41.9)$ & $4(33.3)$ & & \\
\hline & $30 \sim 40$ & $16(25.8)$ & $5(41.7)$ & & \\
\hline & $40 \sim$ & $7(11.3)$ & $3(25.0)$ & & \\
\hline \multirow{2}{*}{ Donor type } & URD & $40(37.0)$ & $4(26.7)$ & 0.616 & 0.432 \\
\hline & RD & $68(63.0)$ & 11(73.3) & & \\
\hline \multirow[t]{2}{*}{ RD donor-recipient relatedness } & Siblings & $62(92.5)$ & $12(100.0)$ & - & 1.000 \\
\hline & Parents (half-match) & $5(7.5)$ & $0(0.0)$ & & \\
\hline \multirow[t]{2}{*}{ Donor-recipient blood type } & mismatch & $41(41.0)$ & $10(66.7)$ & 3.482 & $0.062^{\#}$ \\
\hline & match & $59(59.0)$ & $5(33.3)$ & & \\
\hline \multirow[t]{4}{*}{ HLA } & Identical & $66(70.2)$ & $9(60.0)$ & 1.475 & 0.712 \\
\hline & 1 mismatch & $5(5.3)$ & $1(6.7)$ & & \\
\hline & 2 mismatch & $15(16.0)$ & $3(20.0)$ & & \\
\hline & $>3$ mismatch & $8(8.5)$ & $2(13.3)$ & & \\
\hline \multirow[t]{3}{*}{ Source of graft cells } & BM & $5(4.7)$ & $0(0.0)$ & 2.646 & 0.279 \\
\hline & PBSC & $80(74.8)$ & $9(60.0)$ & & \\
\hline & $\mathrm{BM}+\mathrm{PBSC}$ & $22(20.6)$ & $6(40.0)$ & & \\
\hline \multirow[t]{4}{*}{ Conditioning regimen } & $\mathrm{Bu}+\mathrm{Cy} \pm$ tother (no TBI) & $73(67.0)$ & $9(60.0)$ & 0.965 & 0.866 \\
\hline & $\mathrm{Cy}+\mathrm{TBI} \pm$ other & 13(11.9) & $2(13.3)$ & & \\
\hline & Cy \pm other (No Bu, no TBI) & $8(7.3)$ & $1(6.7)$ & & \\
\hline & Other or unknown & 15(13.8) & $3(20.0)$ & & \\
\hline \multirow[t]{5}{*}{ GVHD prophylaxis } & CSA+ short-term MTX & $27(35.1)$ & $2(25.0)$ & 1.692 & 0.714 \\
\hline & CSA+short-term MTX+ATG & $38(49.4)$ & $6(75.0)$ & & \\
\hline & $\mathrm{CSA}+$ short-term MTX+ATG+MMF & $7(9.1)$ & $0(0.0)$ & & \\
\hline & CSA+short-term MTX+MMF & $2(2.6)$ & $0(0.0)$ & & \\
\hline & Other & $3(3.9)$ & $0(0.0)$ & & \\
\hline \multirow[t]{2}{*}{ Donor-recipient sex match } & Different & $50(53.2)$ & $8(61.5)$ & 0.321 & 0.571 \\
\hline & Same & $44(46.8)$ & $5(38.5)$ & & \\
\hline \multirow[t]{3}{*}{ aGVHD grade (in 30 days) } & No & $94(86.2)$ & 14(93.3) & 0.193 & 1.000 \\
\hline & I-II & 11(10.1) & $1(6.7)$ & & \\
\hline & III-IV & $4(3.7)$ & $0(0.0)$ & & \\
\hline VOD (in 30days) & No & 103(96.3) & 13(86.7) & - & 0.158 \\
\hline & Yes & $4(3.7)$ & 2(13.3) & & \\
\hline EBV infection (in 30 days) & No & $94(86.2)$ & 14(93.3) & 0.591 & 0.690 \\
\hline & Yes & 15(13.8) & $1(6.7)$ & & \\
\hline CMV infection (in 30 days) & Negative & 105(96.3) & $12(80.0)$ & - & $0.038^{\#}$ \\
\hline & Positive & $4(3.7)$ & $3(20.0)$ & & \\
\hline History of CMV infection & No & $96(88.1)$ & 14(93.3) & - & 1.000 \\
\hline & Yes & 13(11.9) & $1(6.7)$ & & \\
\hline Fungus infection before HSCT & No & $90(82.6)$ & $12(80.0)$ & - & 0.729 \\
\hline & Yes & 19(17.4) & $3(20.0)$ & & \\
\hline
\end{tabular}




\begin{tabular}{|c|c|c|c|c|c|}
\hline \multirow[t]{2}{*}{ Variables } & \multirow[t]{2}{*}{ Group } & \multicolumn{2}{|c|}{ Number of patients } & \multirow[t]{2}{*}{$x^{2 *}$} & \multirow[t]{2}{*}{$\mathrm{P}$ vale } \\
\hline & & No-PGF, N (\%) & PGF, N (\%) & & \\
\hline \multirow[t]{3}{*}{ Time to BMT (M) } & $<6$ & $44(43.1)$ & $7(58.3)$ & 0.915 & 0.735 \\
\hline & $6 \sim 12$ & $27(26.5)$ & $2(16.7)$ & & \\
\hline & $12 \sim$ & $31(30.4)$ & $3(25.0)$ & & \\
\hline \multirow[t]{2}{*}{ Infection before BMT } & No & $98(89.9)$ & 13(86.7) & - & 0.657 \\
\hline & Yes & 11(10.1) & $2(13.3)$ & & \\
\hline \multirow{2}{*}{$\begin{array}{l}\text { Bacterial infection post BMT (in } 30 \\
\text { days) }\end{array}$} & No & $65(59.6)$ & $8(53.3)$ & 0.216 & 0.642 \\
\hline & Yes & $44(40.4)$ & $7(46.7)$ & & \\
\hline \multirow[t]{2}{*}{ History of Hepatitis B } & No & $87(79.8)$ & 11(73.3) & - & 0.516 \\
\hline & Yes & $22(20.2)$ & $4(26.7)$ & & \\
\hline \multirow[t]{3}{*}{ MNC infusion number $5 \times 10^{8} / \mathrm{kg}$} & $<5$ & 13(13.1) & $1(8.3)$ & 0.807 & 0.712 \\
\hline & $5-10$ & $70(70.7)$ & $8(66.7)$ & & \\
\hline & $10 \sim$ & $16(16.2)$ & $3(25.0)$ & & \\
\hline \multirow[t]{3}{*}{ CD34+ infusion number $\left(2 \times 10^{6} / \mathrm{kg}\right)$} & $<5$ & $47(57.3)$ & 11(78.6) & 1.918 & 0.372 \\
\hline & $5-10$ & $28(34.1)$ & $3(21.4)$ & & \\
\hline & $10 \sim$ & $7(8.5)$ & $0(0.0)$ & & \\
\hline
\end{tabular}

Note: *Count data was analyzed by Chi-square test and if theoretical frequency of any cell was less than 5, Fish exact test was conducted instead. \#: P<0.1. AML: acute myelogenous leukemia; ALL: acute lymphoblastic leukemia; CML: Chronic myelocytic leukemia; MAL: Mixed lineage acute leukemia; MDS: myelodysplastic syndrome; NHL: Non-Hodgkin lymphoma; PNH: paroxysmal nocturnal hemoglobinuria; SAA: severe aplastic anemia; PNH-AA: paroxysmal nocturnal hemoglobinuria aplastic anemia; CMV: cytomegalovirus; TBI: total body irradiation; CY: cyclophosphamide; CSA: cyclosporin; MTX: methotrexate).

Table 2. Multivariate logistic analysis for risk factors of PGF.

\begin{tabular}{|c|c|c|c|c|c|c|c|}
\hline \multirow[t]{2}{*}{ Risk factors } & \multirow[t]{2}{*}{$\beta$} & \multirow[t]{2}{*}{$S_{b}$} & \multirow[t]{2}{*}{ Wald value } & \multirow[t]{2}{*}{$P$ value } & \multirow[t]{2}{*}{$O R$ value } & \multicolumn{2}{|c|}{$95 \% \mathrm{CI}$ for $\mathrm{OR}$} \\
\hline & & & & & & Lower limit & Upper limit \\
\hline Age of patient & 1.011 & 0.340 & 8.843 & $0.003^{*}$ & 2.747 & 1.411 & 5.347 \\
\hline Donor-recipient blood mismatch & 1.399 & 0.655 & 4.561 & $0.033^{*}$ & 4.051 & 1.122 & 14.629 \\
\hline CMV infection & 2.213 & 0.918 & 5.815 & $0.016^{*}$ & 9.146 & 1.513 & 55.276 \\
\hline
\end{tabular}

*: $\mathrm{P}<0.05$.

Table 3. Donor-recipient blood type

\begin{tabular}{|c|c|c|c|c|c|c|c|c|}
\hline & \multirow[t]{2}{*}{ B } & \multirow[t]{2}{*}{ S.E. } & \multirow[t]{2}{*}{ Wald } & \multirow[t]{2}{*}{ df } & \multirow[t]{2}{*}{ Sig. } & \multirow[t]{2}{*}{$\operatorname{Exp}(B)$} & \multicolumn{2}{|c|}{ 95.0\% C.I.for $\mathrm{EXP}(\mathrm{B})$} \\
\hline & & & & & & & Lower & Upper \\
\hline Major blood group incompatibility & 1.675 & 0.804 & 4.336 & 1 & 0.037 & 5.337 & 1.103 & 25.812 \\
\hline Minor blood group incompatibility & 0.013 & 1.184 & 0.000 & 1 & 0.992 & 1.013 & 0.100 & 10.302 \\
\hline Both blood group incompatibility & 1.711 & 0.838 & 4.164 & 1 & 0.041 & 5.532 & 1.070 & 28.603 \\
\hline Constant & -5.553 & 1.221 & 20.690 & 1 & 0.000 & 0.004 & & \\
\hline
\end{tabular}

\section{Multivariate logistic analysis of PGF (Table 2)}

Based on the results of univariate analysis, variables with a significance level of $\mathrm{P}<0.1$ were used as candidate variables and screened by multivariate logistic regression analysis. Multivariate analysis showed that patient age, donor-recipient blood-type matching and CMV infection (in 30 days) were significant contributors to PGF. Patients were divided into subgroups according to age $<20,20-30,30-40$, and $>40$ years. The risk of PGF increased 2.747-fold (odds ratio $(\mathrm{OR})=2.625,95 \%$ confidence interval: 1.411-5.347) for each increment in age level. Patients with mismatch of donor-recipient blood type (OR = 4.051) or CMV infection (OR $=9.146)$ were at increased risk of PGF.

\section{Donor-recipient blood type (Table 3)}

Blood-type data were available for 115 patients, but lacking for the remaining nine. Sixty-one cases had incompatible blood groups, including major blood group incompatibility in 18 (5with PGF), minor blood group incompatibility in 17 (1 with PGF), and both blood group incompatibilities in 16 (4 with PGF). The associations between PGF and incompatibilities of major or both blood groups were significant, while there was not significant association between PGF and minor blood groups incompatibility.

\section{Discussion}

Allo-HSCT is an effective treatment for malignant hematopoietic and immunodeficiency diseases. Successful transplantation depends on the formation of donor chimerism, in which donor cells are integrated into the recipient's cell population. Reduced donor chimerism is closely related to graft rejection and primary disease reoccurrence, and should therefore be measured dynamically after transplantation. Limitations of the detection method mean that PGF after transplantation has largely been regarded to indicate failure of engrafting. However, improvements in assay technologies for assessing donor chimerism, including conventional cytologic, genetic, 
and molecular biological methods, and the emergence of fluorescent multiplex short tandem repeat loci PCR amplification, has demonstrated that some patients may experience PGF even under conditions of $100 \%$ donor chimersim.

Previous reports have shown incidences of PGF after allo-HSCT of $5-27 \%$, suggesting that it represents a severe post-transplant complication. Patients who experienced PGF showed continuous bilineage or trilineage dysplasia for at least 30 days [4]. Long-term decreases in bilineage or trilineage cells would lead to hemorrhage and elevated infection rates, thus adversely affecting post-transplantation survival. However, the mechanisms responsible for PGF after allo-HSCT remain unclear, and multiple factors may be involved in the occurrence of PGF. Previous reports have focused on two factors: repopulation problems caused by inadequate infusion of hematopoietic stem cells or conditioning-induced hematopoietic stromal cell damage, bone marrow fibrosis or bone marrow suppression during transplantation; and post-transplantation GVHD, VOD and virus infection, which may destroy blood cells and cause PGF [5].

In general, patients under 60 years old are eligible for HSCT, while patients above 60 years or in poor health are considered likely to be intolerant to high-dose radiochemotherapy, and supportive care should be considered instead. Previous reports have shown that mismatch of donor-recipient blood type does not necessarily result in poor transplantation. Compared with ABO-compatible transplantation, ABO-mismatched transplantation showed similar survival time, and GVHD and CMV infection rates. However, mismatched recipients were more likely to undergo immune-mediated hemolysis and delayed erythrocyte engraftment [6-8].

CMV is human herpesviruses that infect $60-80 \%$ of adults, but most cases remain latent over long periods of time. However, after HSCT, patients become immunocompromised and vulnerable to CMV reactivation, leading to subsequent CMV disease in multiple organs. CMV pneumonia may be responsible for $80 \%$ patient death that contracted CMV and could lead to transplantation failure.

CMV may infect the bone marrow and inhibit hematopoiesis directly, or may infect stromal cells and suppress hematopoiesis indirectly [9]. CMV infections in children undergoing HSCT could lead to a decrease in bone stroma secretion factors and poor graft survival. Patients receiving HSCT, especially those with CMV-infection risk factors such as donor-recipient CMV infection status before transplantation, high grades of GVHD, T-cell depletion and conditioning strength, should receive anti-virus therapy. Meanwhile, bone marrow suppression drugs such as ganciclovir should be avoided [10].

There are a few limitations of our study. First, it is a retrospective study with a small number of patients, because the incidence of PGF is low, and clinical cases are quite few. The number of patients analyzed and our data need to be further explored. Another limitation is transplantation characteristics including diagnosis of diseases, conditioning regimen, source of stem cells and GVHD prophylaxis are different in our study, however, these variables were not identified as significant risk factors in univariate or multivariate analysis for PGF.

In conclusion, this study demonstrated that PGF was a common complication after allo-HSCT, with an incidence of $12.1 \%$, and could thus be considered as a potentially major lethal factor in patients undergoing allo-HSCT. Elderly patients or those with incompatible donor-recipient blood matches and/or at high-risk of CMV infection should receive early medical intervention.

\section{Acknowledgement}

This study was supported by National Natural Science Foundation of China (81101471/H1602, 81100387) and PLA Medical Science and Technique Foundation during the 12th Five-Year Plan Period (BWS11J071).

\section{Competing Interests}

The authors have declared that no competing interest exists.

\section{References}

1. Galotto M, Berisso G, Delfino L, et al. Stromal damage as consequence of high-dose chemo/radiotherapy in bone marrow transplant recipients. Exp Hematol. 1999; 27:1460-1466.

2. Deeg HJ, Antin JH. The clinical spectrum of acute graft-versus-host disease. Semin Hematol. 2006; 43:24-31.

3. Bittencourt $\mathrm{H}$, Rocha V, Filion A, et al. Granulocyte colony-stimulating factor for poor graft function after allogeneic stem cell transplantation: 3 days of G-CSF identifies long-term responders. Bone Marrow Transplant. 2005; 36:431-435.

4. Larocca A, Piaggio G, Podesta M, et al. Boost of CD34+-selected peripheral blood cells without further conditioning in patients with poor graft function following allogeneic stem cell transplantation. Haematologica. 2006; 91:935-940.

5. Dominietto A, Raiola AM, van Lint MT, et al. Factors influencing haematological recovery after allogeneic haemopoietic stem cell transplants: graft-versus-host disease, donor type, cytomegalovirus infections and cell dose. Br J Haematol. 2001; 112:219-227.

6. Rowley SD, Liang PS, Ulz L. Transplantation of ABO-incompatible bone marrow and peripheral blood stem cell components. Bone Marrow Transplant. 2000; 26:749-757.

7. Bao L, Huang XJ, Liu KY, et al. Effect of ABO-incompatibility on allogeneic hematopoietic stem cell transplantation. Beijing Da Xue Xue Bao. 2005; 37:126-129.

8. Benjamin RJ, Connors JM, McGurk S, Churchill WH, Antin JH. Prolonged erythroid aplasia after major ABO-mismatched transplantation for chronic myelogenous leukemia. Biol Blood Marrow Transplant. 1998; 4:151-156.

9. Torok-Storb B, Boeckh M, Hoy C, Leisenring W, Myerson D, Gooley T. Association of specific cytomegalovirus genotypes with death from myelosuppression after marrow transplantation. Blood. 1997; 90:2097-2102.

10. Zaucha-Prazmo A, Wojcik B, Drabko K, Choma M, Kowalczyk JR. Cytomegalovirus (CMV) infections in children undergoing hematopoetic stem cell transplantation. Pediatr Hematol Oncol. 2005; 22:271-276. 